\author{
Jakub Kosowski \\ Uniwersytet Marii Curie-Skłodowskiej w Lublinie \\ ORCID: 0000-0001-6888-5771 \\ jakub.kosowski@poczta.umcs.lublin.pl
}

\title{
Glosa do wyroku Sądu Apelacyjnego w Krakowie z dnia 24 września 2015 r. (II AKa 97/15)
}

\author{
Gloss to the Judgement of the Court of Appeal in Kraków \\ of 24 September 2015 (II AKa 97/15)
}

\section{STRESZCZENIE}

Glosa dotyczy kwestii protokołowania w procesie karnym. Autor analizuje aktualne orzecznictwo w omawianym zakresie, wskazując na współczesne założenia przeprowadzania tej czynności procesowej. Dostrzeżone w tym względzie wątpliwości wynikają z ułomności tego sposobu protokołowania, lecz można je wyeliminować za pomocą e-protokołu. W ostatniej części opracowania autor odnotował praktyczne problemy związane z wdrażaniem e-protokołu, a także ocenił proponowane regulacje Ministerstwa Sprawiedliwości, które mają wpłynąć na uproszczenie procedury karnej poprzez zwiększenie efektywności pracy z e-protokołem.

Słowa kluczowe: protokołowanie; e-protokół; formularz uzasadnienia; metodyka protokołowania

Przepisy procesowe nie normują techniki protokołowania. W orzecznictwie aprobuje się, że wypowiedzi osoby przesłuchiwanej są streszczane w protokole, co pozwala formułować tekst w sposób zrozumiały, z pominięciem wypowiedzi nieistotnych dla treści, które utrudniają jej zrozumienie, co mogłoby mieć miejsce przy zapisie dosłownym. Protokół ma utrwalać treść wypowiedzi w sposób oddający istotę rzeczy, powinien stanowić wierne, ściśle odpowiadające rzeczywistej treści odbicie wypowiedzi osoby przesłuchiwanej w zakresie istotnym dla danej sprawy. Protokół może więc zawierać słowa lub zwroty, których przesłuchiwany nie używał. Przepis art. $148 \S 2$ k.p.k. wymaga zamieszczenia w protokole wyjaśnień, zeznań, oświadczeń i wniosków z możliwą dokładnością. Niewątpliwie trafne jest stanowisko, że protokół nie musi stanowić idealnego odzwierciedle- 
nia wypowiedzi osoby przesłuchiwanej, skoro ustawa wymaga umieszczenia w protokole m.in. wyjaśnień „z możliwą dokładnością” (art. 148 § 2), a zatem niedosłownie.

Wyrażona przez Sąd Apelacyjny w glosowanym wyroku teza bez wątpienia zasługuje na aprobatę. Szerszego odniesienia wymagają natomiast kwestie związane w sposób bezpośredni i pośredni z materią wynikającą z wyroku Sądu Apelacyjnego, w szczególności w odniesieniu do wdrożenia tzw. e-protokołu. Glosowany wyrok był już przedmiotem analiz doktryny ${ }^{1}$. Niniejsze opracowanie nie stanowi próby powielenia tych rozważań, jego istotą jest bowiem zwrócenie uwagi na inne aspekty związane z techniką protokołowania i jej współczesnymi wyzwaniami.

Tematyka protokołowania ma niebagatelne znaczenie dla praktyki funkcjonowania procesu karnego. Otóż wpływa ona w sposób istotny na sprawność prowadzenia rozprawy lub posiedzenia, a więc łączy się z zasadą szybkości postępowania, która zakłada rozstrzygnięcie sprawy w rozsądnym terminie ${ }^{2}$.

Analiza przepisu art. $148 \S 2$ k.p.k. prowadzi do wniosku, iż ustawodawca wprowadził kilka wariantów postępowania w zakresie sporządzania protokołu. W pierwszej kolejności należy wskazać na regułę o charakterze podstawowym, tj. zamieszczania wyjaśnień, zeznań, oświadczeń i wniosków z „możliwą dokładnością". Wykładnia literalna tego przepisu prowadzi do wniosku, że skoro wypowiedź ta ma być zamieszczana $\mathrm{z}$ „możliwą dokładnością”, to nie będzie stanowić wiernego odzwierciedlenia słów wypowiedzianych podczas rozprawy lub posiedzenia. Za taką wykładnią przemawia także analiza art. $148 \S 2$ zdanie drugie k.p.k., który stanowi, że osoby biorące udział w czynności mają prawo żądać zamieszczenia w protokole z pełną dokładnością wszystkiego, co dotyczy ich praw i interesów. Ustawodawca przyjął więc, że w świetle reguły określonej mianem podstawowej osoba biorąca udział w czynności może żądać bardziej szczegółowego udokumentowania wypowiedzianych słów. Należy w tym względzie odnieść się do katalogu podmiotowego określonego w art. 148 § 2 zdanie drugie k.p.k. Przepis ten odnosi się do osoby biorącej udział w czynności. Dotyczy to zatem nie tylko stron procesowych, lecz także osobowych źródeł dowodowych, w tym świadków

1 J. Gurgul w bardzo ciekawy sposób zwrócił uwagę na aspekty językowe, puentując swoje opracowanie stwierdzeniem, że czynności przesłuchania i protokołowania powinny być rozważne, nieszablonowe, realizowane według elastycznego algorytmu, ad hoc indywidualizowanego. Zob. J. Gurgul, Glosa do wyroku Sądu Apelacyjnego w Krakowie z dnia 24 września 2015 r., sygn. II AKa 97/15, „Prokuratura i Prawo” 2017, nr 1, s. 146.

2 Zasada szybkości jest wyróżniana przez część przedstawicieli doktryny. Szerzej zob. m.in.: J. Skorupka, [w:] Proces karny, red. J. Skorupka, Warszawa 2018, s. 165-173; K. Zgryzek, [w:] Proces karny, red. K. Marszał, J. Zagrodnik, Warszawa 2017, s. 129-130. 
i biegłych. Podmioty te nie będą mieć problemu z wykazaniem, że potrzeba dokładnego dokumentowania wypowiedzianych słów dotyczy ich praw. Ma to znaczenie dla oceny ich zeznań, ewentualnych sprzeczności czy też w wyjątkowej sytuacji odpowiedzialności za składanie fałszywych zeznań. Podobna argumentacja może być aktualna w odniesieniu do stron procesowych, którym z perspektywy rozstrzygnięcia sprawy będzie zależało na ujęciu w protokole pełnej wypowiedzi, kiedy uznają, że wypowiedź podyktowana przez przewodniczącego składu orzekającego zniekształca rzeczywistą wypowiedź świadka. Przytoczone w art. $148 \S 2$ zdanie drugie k.p.k. kryterium ma charakter niezwykle szeroki i zmniejsza władzę dyskrecjonalną przewodniczącego składu orzekającego. W sytuacji kiedy przewodniczący składu orzekającego nie zrealizuje przedmiotowego żądania, istnieje możliwość skorzystania z instytucji przewidzianej w art. 152 k.p.k., czyli sprostowania protokołu. W przypadku nieprzychylenia się do wniosku o sprostowanie protokołu sąd (skład orzekający) wydaje postanowienie, które jest niezaskarżalne. Do powyższego wniosku prowadzi analiza art. 153 k.p.k., który nie wprowadza wprost możliwości zaskarżenia orzeczenia, a ponadto analiza normy ogólnej odnoszącej się do zaskarżania postanowień, tj. art. 459 § 2 k.p.k. T. Grzegorczyk ${ }^{3}$ słusznie jednak zauważył, że wniosek o sprostowanie zawsze dołącza się do protokołu, co umożliwia zapoznanie się z nim sądowi drugiej instancji.

Bogate orzecznictwo w przedmiocie art. 148 k.p.k. umożliwia sformułowanie kilku wytycznych w zakresie postępowania organu prowadzącego czynność procesową. Najbardziej powszechny w praktyce jest system protokołowania polegający na streszczeniu przez organ procesowy w protokołach wypowiedzi osób przesłuchiwanych, co pozwala formułować tekst w sposób zrozumiały, z pominięciem różnych ułomności wypowiedzi, które nie są istotne dla treści przekazu i tylko utrudniają jego zrozumienie ${ }^{4}$. Glosowane orzeczenie nawiązuje do dotychczasowej linii orzeczniczej z uwagi na fakt, iż Sąd Apelacyjny w Krakowie uznał, że protokół ma utrwalać wypowiedź w sposób oddający jej istotę, co oznacza, że może zawierać słowa i zwroty, których przesłuchiwany nie używał, o ile są one użyteczne do osiągnięcia celu protokołowania i nie deformują sensu wypowiedzi ${ }^{5}$.

3 T. Grzegorczyk, Kodeks postepowania karnego. Komentarz, t. 1, Warszawa 2014, s. 527.

4 Wyrok SA w Krakowie z dnia 14 września 1995 r., II AKr 232/95, LEX nr 24905. Zob. także: T. Grzegorczyk, op. cit., s. 519-520; F. Prusak, Komentarz do kodeksu postepowania karnego, t. 1, Warszawa 1999, s. 463; J. Skorupka, [w:] Kodeks postępowania karnego. Komentarz, red. R.A. Stefański, S. Zabłocki, t. 1, Warszawa 2003, s. 1233; Z. Gostyński, J. Bratoszewski, [w:] Kodeks postępowania karnego. Komentarz, red. R.A. Stefański, S. Zabłocki, t. 1, s. 707; M. Kurowski, [w:] Kodeks postępowania karnego. Komentarz, red. D. Świecki, t. 1, Warszawa 2017, s. 568; A. Sakowicz, [w:] Kodeks postepowania karnego. Komentarz, red. A. Sakowicz, Warszawa 2015, s. 351; S. Steinborn, [w:] Kodeks postępowania karnego. Komentarz, red. L.K. Paprzycki, t. 1, Warszawa 2013, s. 512; D. Jagiełło, Przestuchanie jako czynność dowodowa, Warszawa 2017, s. 200.

Wyrok SA w Krakowie z dnia 17 maja 2001 r., II AKa 100/01, KZS 2001, z. 6, poz. 37; wyrok SA w Krakowie z dnia 14 marca 2007 r., II AKa 13/07, KZS 2007, z. 5, poz. 42; wyrok SN z dnia 27 
Warto w tym względzie przytoczyć pogląd R. Ponikowskiego ${ }^{6}$ sformułowany na gruncie obowiązywania k.p.k. z 1969 r., który wskazał, że treść każdego protokołu, stanowiąca swoistą transformację odbieranych wypowiedzi na język protokołu, powinna być zwięzła, rzeczowa, przystosowana do potrzeb wymiaru sprawiedliwości, nie zatracając przy tym wierności oryginału i zachowując wszystko, co może mieć znaczenie w toczącym się postępowaniu. Powyższe metody na trwałe wpisały się w praktykę polskiego wymiaru sprawiedliwości, podobnie zresztą jak metodyka pracy części sędziów oparta na dyktowaniu do protokołu wypowiedzi uczestników postępowania. Ciekawa w tym względzie jest analiza wpływu obranych metod protokołowania na szybkość prowadzenia postępowania. Powstaje pytanie, czy sprawniejszym (szybszym) sposobem jest dyktowanie do protokołu przez sędziego ${ }^{7}$ czy też dokumentowanie in extenso wypowiedzi uczestnika procesu $^{8}$. W mojej ocenie jednoznaczna odpowiedź na tak postawione pytanie nie jest możliwa z uwagi na różną metodykę pracy organów procesowych, sprawność protokolantów, a także poziom intelektualny (sprawność wypowiedzi) reprezentowany przez uczestnika postępowania.

Mając na uwadze przytoczoną linię orzeczniczą, pojawia się pytanie, czy taka forma protokołowania spełnia dyspozycję przepisu art. $148 \S 2$ zdanie pierwsze k.p.k., który wskazuje na obowiązek dokumentowania „z możliwą dokładnością”. W literaturze powstają wątpliwości, czy zbyt daleko nie odbiega to od rzeczywistej treści ustnego przekazu przez jego wygładzenie i używanie określeń niekoniecznie synonimicznych, a także czy to nie utrudnia następnie rzeczywistej kontroli orzeczenia

lutego 1971 r., III KR 210/70, OSNKW 1971, nr 9, poz. 133, Legalis 15240. Zob. także: T. Grzegorczyk, op. cit., s. 520; Z. Pachowicz, [w:] Kodeks postępowania karnego. Komentarz, red. A. Sakowicz, Warszawa 2015, s. 343; H. Paluszkiewicz, [w:] Kodeks postępowania karnego. Komentarz, red. K. Dudka, Warszawa 2018, s. 310; A. Sakowicz, op. cit., s. 351; M. Cieślak, Z. Doda, Przegląd orzecznictwa Sądu Najwyższego w zakresie postępowania karnego za drugie pótrocze 1971 r., „Wojskowy Przegląd Prawniczy" 1972, nr 2, s. 258; S. Steinborn, op. cit., s. 512. Por. P. Hofmański, E. Sadzik, K. Zgryzek, Kodeks postępowania karnego. Komentarz, t. 1, Warszawa 2011, s. 834.

6 R. Ponikowski, Procesowe formy utrwaleń czynności dowodowych w sprawach karnych, Wrocław 1978, s. 66. Podobnie: E. Stodolak, Technika protokołowania, „Demokratyczny Przegląd Prawniczy" 1948, nr 6, s. 45.

7 Na sprawność postępowania, ale i zgodność tego zachowania z treścią art. 148 k.p.k., zwrócili uwagę: M. Kurowski, op. cit., s. 568; T. Grzegorczyk, op. cit., s. 519; A. Sakowicz, op. cit., s. 351; P. Hofmański, E. Sadzik, K. Zgryzek, op. cit., s. 834; S. Steinborn, op. cit., s. 511. R. Ponikowski (op. cit., s. 68), dostrzegając zalety tej formy, uznał natomiast, że dyktowanie rozprasza uwage przewodniczącego, utrudnia koncentrację na przeprowadzanej czynności oraz w istotny sposób przedłuża czas trwania czynności, wywołując niekiedy wrażenie podporządkowania samej czynności jej protokolarnemu utrwaleniu.

8 Problem ten nie będzie rzecz jasna występował tak szeroko w postępowaniu przygotowawczym z uwagi na charakter prowadzonych tam czynności oraz swoistą akceptację treści protokołu poprzez podpis osób w nim uczestniczących i możliwość zgłaszania uwag przed podpisaniem protokołu. 
w zakresie prawidłowości oceny dowodów i ustalanych na ich podstawie faktów ${ }^{9}$. Jest to kluczowa kwestia z perspektywy oceny trafności glosowanego wyroku. W pierwszej kolejności należy zauważyć, że ustawodawca przyjął założenie, iż w protokole nie zostanie wiernie oddana wypowiedź uczestnika postępowania. Świadczy o tym użycie stwierdzenia „,z możliwą dokładnością”, o czym była już mowa powyżej. Nie można więc mówić o uchybieniu procesowym w sytuacji wprowadzenia choćby takich uproszczeń, jak wskazane w glosowanym wyroku. Chcąc uzyskać odmienny efekt, należałoby wprowadzić zmianę w treści art. 148 § 2 zdanie pierwsze k.p.k., np. poprzez wprowadzenie zwrotu ,z pełną dokładnością" wykorzystanego w zdaniu drugim tego paragrafu ${ }^{10}$. Zwrot ,z możliwą dokładnością” stanowi bowiem klauzulę generalną, która będzie interpretowana w oparciu o orzecznictwo i literaturę przedmiotu. Poza pojedynczymi wypowiedziami doktryny ${ }^{11}$ metodyka protokołowania wskazana w glosowanym orzeczeniu jest powszechnie akceptowana. Wydaje się, że wynika to z wieloletniej praktyki oraz z potrzeby zapewnienia sprawności działania ${ }^{12}$. Podobnie zresztą jak kwestia pomijania pewnych wypowiedzi w protokole. Należy tu przytoczyć stanowisko Sądu Apelacyjnego w Lublinie, który uznał, że prawidłowo sporządzony protokół powinien być wierną kopią rejestracji magnetowidowej przesłuchania, a więc zawierać treść postawionego pytania i faktyczną odpowiedź świadka ${ }^{13}$. Bez wątpienia należy się zgodzić z Z. Pachowiczem ${ }^{14}$, że powyższego poglądu nie uzasadnia treść art. 148 k.p.k. Ponadto gdyby takie były wymagania odnośnie do protokołu, to rzeczą zbędną byłoby dodatkowe utrwalanie dźwięku lub obrazu z przesłuchania. Autor ten trafnie natomiast odniósł stanowisko Sądu Apelacyjnego do zapisu przekładu dźwięku z przesłuchania utrwalonego na taśmie magnetowidowej. W przedmiotowej kwestii Sąd Apelacyjny w Krakowie wprost uznał, iż stwierdzenie ,z możliwą dokładnością” należy rozumieć w ten sposób, że nie chodzi tutaj o dosłowne przytoczenie wypowiedzi ${ }^{15}$. W literaturze wskazano

9 S. Steinborn, op. cit., s. 512; T. Grzegorczyk, op. cit., s. 520. Por. J. Gurgul, op. cit., s. 139; D. Jagiełło, op. cit., s. 202.

10 Tak Z. Pachowicz, op. cit., s. 343; J. Skorupka, op. cit., s. 1233; Z. Gostyński, J. Bratoszewski, op. cit., s. 707.

${ }^{11}$ Na pewne wątpliwości w tym zakresie zwrócili uwagę m.in.: S. Steinborn, op. cit., s. 512; T. Grzegorczyk, op. cit., s. 520.

12 Dbałość o sprawność postępowania mają zapewnić także inne instytucje służące zmniejszeniu stopnia sformalizowania procesu, jak np. art. 325h k.p.k., czyli tzw. protokołu ograniczonego przy dochodzeniu, czy też art. 145 k.p.k., który dotyczy ograniczenia protokołu przy utrwalaniu czynności za pomocą stenogramu.

13 Wyrok SA w Lublinie z dnia 22 października 2003 r., II AKa 115/03, „Prokuratura i Prawo” 2004, nr 10, poz. 30, Legalis 70047.

14 Z. Pachowicz, op. cit., s. 343.

15 Wyrok SA w Krakowie z dnia 9 marca 2011 r., II AKa 22/11, KZS 2011, nr 5, poz. 49, Legalis 78685. Podobnie: M. Kurowski, op. cit., s. 568; A. Sakowicz, op. cit., s. 351; S. Steinborn, op. cit., s. 512; R. Ponikowski, op. cit., s. 65. 
również, że nie ma podstaw do pomijania w protokole wyrażeń wulgarnych lub obraźliwych ${ }^{16}$. Z poglądem tym należy się zgodzić, jednakże analiza praktyki wymiaru sprawiedliwości w sprawach karnych prowadzi do wniosku, że dokumentowanie tego typu słownictwa odbywa się zazwyczaj wyłącznie wtedy, gdy ma to związek z zarzucanym czynem (np. znieważeniem).

Podsumowując, należy stwierdzić, że jeżeli protokół nie będzie zawierał treści sprzecznych z istotą słów wypowiedzianych przez uczestnika postępowania, to pozostanie to w zgodzie z obecnym brzmieniem art. 148 § 2 zdanie pierwsze k.p.k. Przyjęcie takiego stanowiska generuje kolejne pytanie: Czy swoiste „wygładzanie” protokołu nie utrudni kontroli odwoławczej? Co do tego bardzo trafnie zauważył S. Steinborn ${ }^{17}$, że język i styl wypowiedzi są ważnymi źródłami informacji o osobie przesłuchiwanej, m.in. o jej pochodzeniu, wykształceniu czy osobowości, a tym samym użycie przez świadka w pewnym fragmencie wypowiedzi innego stylu niż zwykle może świadczyć o tym, że nie jest to jego własne spostrzeżenie. Do tych argumentów warto dodać jeszcze kwestie zachowania osoby wypowiadającej dane słowa oraz stopnia pewności wypowiadanych poglądów (np. świadek z wątpliwościami opowiada przebieg zdarzenia, w protokole zaś wskazano, że potwierdził wersję oskarżenia). Dotychczasowa praktyka protokołowania często uniemożliwia właśnie taką ocenę informacji zawartych w protokole. Powstaje zatem pytanie: Czy należy optować za zmianą art. $148 \S 2$ zdanie pierwsze k.p.k. poprzez wskazanie obowiązku dokumentowania „,z pełną dokładnością” wszystkich wypowiedzi, analogicznie jak ma to miejsce w zdaniu drugim przytoczonego paragrafu? Wydaje się, że taka zmiana w sposób istotny wydłużyłaby postępowania karne, a tym samym byłaby niepożądana z perspektywy zasady szybkości postępowania. Zasadne jest jednak przeanalizowanie tej problematyki w kontekście nowoczesnych technologii, o czym będzie mowa w dalszej części niniejszej glosy.

Nagrywanie dźwięku i obrazu pozwala utrwalić całą treść wypowiedzianą przez uczestnika postępowania oraz jego emocje i sposób zachowania. Obecnie Kodeks postępowania karnego umożliwia prowadzenie nagrania dźwięku i obrazu z rozprawy; zapis ten stanowi następnie załącznik do protokołu (art. 147 § 3a k.p.k.). Co istotne, taka forma nie zwalnia $\mathrm{z}$ obowiązku protokołowania $\mathrm{w}$ formie pisemnej zgodnie $\mathrm{z}$ art. 148 k.p.k., a tym samym nie redukuje stopnia formalizmu procesowego.

Odmiennie kwestię tę reguluje Kodeks postępowania w sprawach o wykroczenia. W 2014 r. wprowadzono zmiany ${ }^{18}$, które korespondowały z systemem wdrażanym w sprawach cywilnych. Art. $37 \S 2$ k.p.w. stanowi, że z rozprawy sporządza się protokół utrwalający przebieg rozprawy za pomocą urządzenia rejestrującego

16 S. Steinborn, op. cit., s. 512; T. Grzegorczyk, op. cit., s. 519; J. Gurgul, op. cit., s. 142.

17 S. Steinborn, op. cit., s. 512-513. Podobnie: T. Grzegorczyk, op. cit., s. 519.

18 Ustawa z dnia 4 kwietnia 2014 r. o zmianie ustawy - Kodeks postępowania w sprawach o wykroczenia (Dz.U. 2014, poz. 579), dalej jako: k.p.w. 
dźwięk albo dźwięk i obraz. Dodatkowo sporządza się protokół skrócony, przy czym zawiera on ściśle określone elementy (art. 37 § k.p.w.), a więc nie generuje przedłużenia postępowania. Powyższe regulacje, jeśli chodzi o generalia, należy ocenić pozytywnie, lecz ich stosowanie w praktyce już napotyka na liczne trudności. Praktyczne problemy można podzielić na kilka podstawowych grup. Do pierwszej można zaliczyć kwestie techniczne związane z wyposażeniem (sprzętem), jego montażem, awaryjnością, bieżącą eksploatacją. Ustawodawca wprowadził w tym zakresie bardzo precyzyjne regulacje dotyczące zastosowania metod dotychczasowych (tradycyjnego pisemnego protokołu) z uwagi na „,względy techniczne” (art. 37 $\S 7$ k.p.w.). Druga grupa problemów to sprawność protokolantów w posługiwaniu się sprzętem i oprogramowaniem dedykowanym do prowadzenia protokołowania. Trzecia grupa to kwestie podejścia psychologicznego - ostrożność czy wręcz niechęć pracowników wymiaru sprawiedliwości do stosowania tego systemu, co jest charakterystyczne dla zachowania przy wprowadzaniu istotnych zmian i nowości; można to było zaobserwować także podczas wcześniej wdrażanych reform. Ostatnia grupa to kwestia metodyki pracy sędziego. W tym względzie można wymienić kilka podstawowych wariantów, w tym: 1) dyktowanie do protokołu - analogicznie jak przed wdrożeniem e-protokołu, 2) pozostawienie pełnej swobody protokolantowi $\mathrm{w}$ doborze treści ujmowanych $\mathrm{w}$ protokole, przy czym $\mathrm{w}$ tej grupie znajdują się protokolanci dokumentujący szeroko wypowiedzi, lecz również tacy, którzy robią to hasłowo, 3) dyktowanie do protokołu wyłącznie podstawowych elementów (adnotacji), w tym np. wniosków, które wynikają z zeznań świadka.

Praktyka pokazuje, że do wymienionych powyżej wariantów podstawowych można dodać wiele modyfikacji wynikających z indywidualnego podejścia organów procesowych do omawianej kwestii. Wydaje się, że praktyką najmniej pożądaną $\mathrm{w}$ świetle intencji ustawodawcy jest dyktowanie bardzo obszernych wypowiedzi do protokołu. Rozmawiając z sędziami, bardzo często otrzymywałem odpowiedź, że jest to potrzebne do sporządzenia uzasadnienia, co ma usprawnić późniejszą pracę nad jego przygotowywaniem. $Z$ tak postawioną tezą trudno jest polemizować, jednakże wynika to moim zdaniem z przyjętej od lat praktyki tworzenia uzasadnień. Są one niezwykle obszerne, a na ich objętość często wpływa kopiowanie dużej części zeznań świadków ujętych w protokole rozprawy. Wydaje się więc, że bez gruntownej zmiany w tym zakresie wdrożenie e-protokołu według intencji ustawodawcy będzie bardzo trudne.

Ze zdiagnozowanymi problemami korespondują prace legislacyjne prowadzone przez Ministerstwo Sprawiedliwości. Zgodnie z założeniami jeden z projektów nowelizacji ustawy Kodeks postępowania karnego oraz niektórych innych ustaw zmierza do zlikwidowania zbędnych formalizmów w postępowaniu, których istnienie samo przez się przedłuża w praktyce bieg postępowania. Chodzi przede wszystkim o wprowadzenie ujednoliconych formularzy uzasadnień wyroków sądów pierwszej i drugiej instancji. Należy podkreślić, że prawidłowo opracowane 
wzory formularzy pozwolą na zawarcie w nich wszelkich wymaganych ustawą procesową treści, które są niezbędne dla wyjaśnienia powodów wydania danego wyroku, wywiedzenia środka zaskarżenia oraz oceny zasadności tego wyroku przez sąd odwoławczy. W praktyce uzasadnienia wyroków są bardzo obszerne - liczą po kilkanaście, kilkadziesiąt, nierzadko nawet po kilkaset stron, a ich sporządzanie zajmuje sędziom wiele czasu. Co więcej, w razie gdy sędzia w tym samym czasie kończy więcej spraw i wpływają w nich wnioski o sporządzenie uzasadnienia wyroku, skumulowanie prac nad nimi powoduje wydłużenie postępowania w tych sprawach nieraz o wiele tygodni ${ }^{19}$.

Przedmiotowy projekt rozwiązuje kilka kluczowych problemów zgłaszanych na etapie dotychczasowego wdrażania e-protokołu, w tym np. konieczność ujęcia na nagraniu ustnego uzasadnienia wyroku przy nieobecności uczestników postępowania. Projektowany art. $418 \S 3$ k.p.k. wyłącza z tego obowiązku sytuacje, gdy nikt się nie stawił. Ponadto według projektowanych nowych przepisów art. $424 \S 4$ i 5 k.p.k. uzasadnienie wyroku sporządza się na formularzu według wzoru, który jest ustalany w drodze rozporządzenia Ministra Sprawiedliwości.

Proponowane przez Ministerstwo Sprawiedliwości zmiany należy ocenić bardzo pozytywnie. Bez wątpienia wspomogą one wdrażanie e-protokołu w postępowaniu w sprawach o wykroczenia, a zapewne w najbliższej przyszłości też w sprawach o przestępstwa. Wydaje się, że nie da się odejść od reformy procedury karnej zakładającej jej elektronizację i odformalizowanie ${ }^{20}$. W pierwszej kolejności jest to związane z rozwojem nowoczesnych technologii, sprzętu i oprogramowania. Kluczowym celem jest jednak zapewnienie szybkości postępowania.

\section{BIBLIOGRAFIA}

Cieślak M., Doda Z., Przegląd orzecznictwa Sądu Najwyższego w zakresie postępowania karnego za drugie pótrocze 1971 r., „Wojskowy Przegląd Prawniczy” 1972, nr 2.

Gostyński Z., Bratoszewski J., [w:] Kodeks postępowania karnego. Komentarz, red. R.A. Stefański,

S. Zabłocki, t. 1, Warszawa 2003.

Grzegorczyk T., Kodeks postepowania karnego. Komentarz, t. 1, Warszawa 2014.

Gurgul J., Glosa do wyroku Sądu Apelacyjnego w Krakowie z dnia 24 września 2015 r., sygn. II AKa 97/15, „Prokuratura i Prawo” 2017, nr 1.

Hofmański P., Sadzik E., Zgryzek K., Kodeks postępowania karnego. Komentarz, t. 1, Warszawa 2011. Jagiełło D., Przestuchanie jako czynność dowodowa, Warszawa 2017.

19 Uzasadnienie do projektu z dnia 4 grudnia 2018 r. ustawy o zmianie ustawy - Kodeks postępowania karnego oraz niektórych innych ustaw, UD465, legislacja.rcl.gov.pl, s. 2.

20 Zob. J. Kosowski, Odformalizowanie i elektronizacja jako kierunek rozwoju postepowania karnego, [w:] e-Wymiar sprawiedliwości w aspekcie europejskim, red. B. Śliwczyński, L. Łuczak-Noworolnik, Poznań 2016, s. 104-105. 
Kosowski J., Odformalizowanie i elektronizacja jako kierunek rozwoju postępowania karnego, [w:] e-Wymiar sprawiedliwości w aspekcie europejskim, red. B. Śliwczyński, L. Łuczak-Noworolnik, Poznań 2016.

Kurowski M., [w:] Kodeks postepowania karnego. Komentarz, red. D. Świecki, t. 1, Warszawa 2017. Pachowicz Z., [w:] Kodeks postepowania karnego. Komentarz, red. A. Sakowicz, Warszawa 2015.

Paluszkiewicz H., [w:] Kodeks postępowania karnego. Komentarz, red. K. Dudka, Warszawa 2018.

Ponikowski R., Procesowe formy utrwaleń czynności dowodowych w sprawach karnych, Wrocław 1978.

Prusak F., Komentarz do kodeksu postępowania karnego, t. 1, Warszawa 1999.

Sakowicz A., [w:] Kodeks postępowania karnego. Komentarz, red. A. Sakowicz, Warszawa 2015.

Skorupka J., [w:] Kodeks postępowania karnego. Komentarz, red. R.A. Stefański, S. Zabłocki, t. 1, Warszawa 2003.

Skorupka J., [w:] Proces karny, red. J. Skorupka, Warszawa 2018.

Steinborn S., [w:] Kodeks postępowania karnego. Komentarz, red. L.K. Paprzycki, t. 1, Warszawa 2013.

Stodolak E., Technika protokołowania, „Demokratyczny Przegląd Prawniczy” 1948, nr 6.

Ustawa z dnia 4 kwietnia 2014 r. o zmianie ustawy - Kodeks postępowania w sprawach o wykroczenia (Dz.U. 2014, poz. 579).

Wyrok SA w Krakowie z dnia 14 września 1995 r., II AKr 232/95, LEX nr 24905.

Wyrok SA w Krakowie z dnia 17 maja 2001 r., II AKa 100/01, KZS 2001, z. 6, poz. 37.

Wyrok SA w Lublinie z dnia 22 października 2003 r., II AKa 115/03, „Prokuratura i Prawo” 2004, nr 10, poz. 30, Legalis 70047.

Wyrok SA w Krakowie z dnia 14 marca 2007 r., II AKa 13/07, KZS 2007, z. 5, poz. 42.

Wyrok SA w Krakowie z dnia 9 marca 2011 r., II AKa 22/11, KZS 2011, nr 5, poz. 49, Legalis 78685. Wyrok SA w Krakowie z dnia 24 września 2015 r., II AKa 97/15, „Prokuratura i Prawo” 2016, nr 6, poz. 36.

Wyrok SN z dnia 27 lutego 1971 r., III KR 210/70, OSNKW 1971, nr 9, poz. 133, Legalis 15240.

Zgryzek K., [w:] Proces karny, red. K. Marszał, J. Zagrodnik, Warszawa 2017.

\section{SUMMARY}

The gloss refers to the issue of protocolling in a criminal trial. The author analyzes the current case law in the discussed scope, pointing to the current assumptions of conducting this procedural act. In this respect, doubts arise due to the disability of this method of protocolling, which can be eliminated by means of the e-protocol. In the last part of the study, the author points out the practical problems related to the implementation of the e-protocol, as well as evaluates the proposed regulations of the Ministry of Justice, which are to simplify the penal procedure by increasing the efficiency of work with the e-protocol.

Keywords: protocolling; e-protocol; warrant form; methodology of protocolling 